\title{
perifèria
}

Número 10, Junio 2009

www.periferia.name

\section{Ciudad y vida urbana: un esbozo teórico}

\author{
Martha Cecilia Cedeño Pérez \\ Instituto Catalán de Antropología ${ }^{1}$
}

\section{Resumen}

En este artículo se retoman algunos elementos teóricos fundamentales que ayudan a comprender la noción de ciudad y vida urbana, entendida ésta como el conjunto de relaciones de carácter efímero y fragmentario que se establece entre individuos que ocupan, se desplazan, utilizan los espacios públicos de las grandes ciudades. Y para ello se recurre a los planteamientos básicos de los precursores de una ciencia que se preocupa por estudiar los fenómenos sociales que tienen lugar en el seno de las urbes modernas en donde se desarrolla y manifiesta un modo de vida singular. Se trata de hacer un esbozo general de los principales planteamientos que aportan luces en la comprensión de la ciudad y la vida que contiene, desde aquellos paradigmáticos de la Escuela de Chicago hasta tendencias teóricas más recientes que aportan nuevas perspectivas en el estudio del hecho urbano.

Palabras clave: ciudad, vida urbana, espacio público.

\begin{abstract}
This article presents some of the most fundamental theoretical elements that allow understanding concepts such as Urban Life and City; places and relationships made out of ephemeral and fragmental interactions among individuals that occupy, move and use Public Spaces in the city.

In order to explain this phenomenon, authors that have established fundamental knowledge on how relationships and movement determine this Life Style in big cities are visited. In that sense, this work presents and overview that travels since the Chicago School through contemporary perspectives on that matter.
\end{abstract}

Key words: City, urban life, public space.

\footnotetext{
${ }^{1}$ Enviar correspondencia a: lunera2107@gmail.com
} 


\section{perifèria}

Número 10, Junio 2009

www. periferia. name

\section{Algunos elementos iniciales}

Los teóricos de la Escuela de Chicago de la segunda y tercera década del siglo pasado, marcaron un hito en el estudio de la ciudad y esas formas sociales singulares que en ella se pueden percibir. Pero ellos no partieron de cero. ${ }^{2}$ Antes Georg Simmel había desarrollado un trabajo casi silencioso en Alemania intentando esbozar los argumentos de una sociología que diera cuenta también de esas agitaciones visibles en las grandes urbes y es poco lo que se puede decir que no se sepa ya con respecto a la importancia de sus hallazgos, su incidencia y vigencia para explicar la vida que surge en las ciudades. Gabriel Tarde también ha sido evocado como precursor de unas ciencias sociales de esa inestabilidad crónica que caracteriza la vida urbana. ${ }^{3}$ Luego, Park, Thomas, Burguess, Thrasher, Wirth y los demás chicaguianos hicieron una serie de aportes valiosos sin los cuales hoy no se podrían comprender algunos fenómenos propios de las sociedades urbanícolas. Sin embargo, se les critica un cierto determinismo en su visión acerca de la forma en que las urbes como Chicago estaban condenadas a mantener relaciones de marginación hacia los sectores más desfavorecidos, quizá por su misma concepción de desarrollo de la ciudad a partir de la competitividad ecológica propia del darwinismo social en que se inspiraban. No obstante, a partir de trabajos como los de aquellos primeros discípulos de William $\mathrm{H}$. Thomas en Chicago se empiezan a desmadejar nociones fundamentales que contribuyen a la comprensión de ese

\footnotetext{
2 En algunos textos se presenta ese recorrido de una manera sistemática y clara, como, entre otros, los de Ulf Hannerz, Exploración de la ciudad, Fondo de Cultura Económica, México, 1986; Gianfranco Bettin, Los sociólogos de la ciudad, Gustavo Gili, Barcelona, 1982; Jean Remy y Liliane Voyé, La ciudad y la urbanización, Instituto de Estudios de Administración Local, Madrid, 1976.

${ }^{3}$ I saac Joseph elabora una analogía interesante entre algunos presupuestos teóricos sobre el público y la muchedumbre desarrollados por Gabriel Tarde en su psicología social y los trazados por Park en su artículo "The Crowd and the Public", sobre la dimensión efímera de las conductas colectivas. Allí muestra algunos rasgos coincidentes de los dos estudiosos a la hora de comprender ciertos comportamientos sociales en marcos urbanos. Véase "Tarde avec Park. A quoi servent les foules?", 2001, http://multitudes.samizdat. net/article.php3?id_article=76
} 


\section{perifèria}

Número 10, Junio 2009

\section{www.periferia.name}

fenómeno social urbano, en especial por lo que hace a singularidades y regularidades visibles en el comportamiento de las personas en el medio citadino:

Gran parte de los habitantes de la ciudad, incluidos aquellos que viven en viviendas populares y apartamentos (...) se cruzan, pero no se conocen entre ellos (...) Esto permite a los individuos pasar rápidamente y fácilmente de un ambiente moral a otro, y alienta el fascinante aunque peligroso experimento de vivir al mismo tiempo en mundos diversos contiguos y sin embargo completamente separados. Todo ello tiende a conferir a la vida ciudadana un carácter superficial y casual, a complicar las relaciones sociales y producir nuevos y divergentes tipos de individuos...

La ciudad no sólo hace posible que distintas personas tengan a la vez distintas relaciones, sino que éstas posean un carácter de extrañamiento, superficialidad y transitoriedad. Esa idea de la dislocación y heterogeneidad en las relaciones sociales urbanas, tema recurrente en Park, es sin duda una deuda con algunos trabajos de Simmel, que años antes había percibido cómo en la ciudad se daba una "acrecentación de la vida nerviosa", una excitación de los sentidos -especialmente de la vista, producto de la sobreexposición a estímulos de toda laya a que se ven sometidos los habitantes de la urbe. En esas condiciones de lo que podríamos llamar irritación anímica surgen ciertos comportamientos y actitudes propias de la vida en la metrópoli que son justamente las que permiten vivir en ella sin sobresaltos mayores, pues

... si al contacto constantemente externo con innumerables personas debieran responder tantas reacciones internas como en la pequeña ciudad, en la que se conoce a todo el mundo con el que uno se tropieza y se tiene una relación positiva con cada uno, entonces uno se atomizaría

\footnotetext{
4 Robert E. Park, "The city: suggestions for the investigation of human behavior in the urban environment", en The city: suggestions for the investigation of human behavior in the urban environment, Midway Reprint, pp. 40-41. Sobre este tema véase también Hannerz, Exploración de la ciudad, pp. 35-37
} 


\section{perifèria}

Número 10, Junio 2009

\section{www. periferia.name}

internamente por completo y caería en una constitución anímica inimaginable. En parte esta circunstancia psicológica, en parte el derecho a la desconfianza que tenemos frente a los elementos de la vida de la gran ciudad que nos rozan ligeramente en efímero contacto, nos obligan a esta reserva, a consecuencia de lo cual a menudo ni siquiera conocemos de vista a vecinos de años y que tan a menudo nos hace parecer a los ojos de los habitantes de las ciudades pequeñas como fríos y sin sentimientos. ${ }^{5}$

Esa combinación entre proximidad y distanciamiento marca de manera importante el carácter del urbanita sobre el que Simmel desvela dos actitudes fundamentales que son internalizadas por aquél: la actitud blasé y la reserva. La actitud blasé (de indiferencia o desgano frente a las cosas) es la respuesta del individuo a la rapidez y las contradicciones de la estimulación nerviosa y está asentada en la relación de los sujetos con los objetos. La reserva es necesaria para sobrellevar el anonimato de la calle, constituyéndose también en la base para la libertad del individuo, puesto, asentada dentro de las relaciones entre los sujetos, consiste básicamente no en ocultar las identidades sino más bien en disimularlas, en mantenerlas protegidas en todo momento por una especie de película que permita salir airoso de las situaciones comprometidas que puedan sobrevenir en la calle. El hombre y la mujer metropolitanos aspiran en principio, en efecto, a ser tomados por lo que pretenden parecer y eso garantiza al menos en la teoría que, cuando se cruzan con alguien por la calle, se reserven el derecho de mostrarse como realmente consideran que son; en eso radica la fuerza de su libertad. Esto no significa que los urbanitas no experimenten todos los matices de la vida emocional, pero se escamotean a la atención ajena. Esas actitudes corresponden a la "inatención de urbanidad" de la que habla Goffman, aquel mecanismo conductual que hace posible

\footnotetext{
${ }^{5}$ Georg Simmel, "Las grandes urbes y la vida del espíritu”, en El individuo y la libertad, Península, 2 da. Edición, Barcelona, 1998, p. 253
} 


\section{perifèria}

Número 10, Junio 2009

\section{www.periferia.name}

las relaciones en público y que también deja traducir la confirmación de una confianza mutua basada en una política de la cortesía y la indiferencia. ${ }^{6}$

En ese sentido la figura del extranjero simmeliano reflejaría muy bien la esencia de la vida urbana, sobre todo en lo que se refiere a la movilidad, a esa relación de distancia/proximidad que, por otra parte, se podría interpretar también como una metáfora de la modernidad, pues ésta se enraíza y se relaciona fuertemente con la vida metropolitana. El extranjero es "el emigrante en potencia, que, aunque se haya detenido, no se ha asentado completamente", ${ }^{7}$ de ahí que su esencia sea "movible, entra ocasionalmente en contacto con todos los elementos del grupo, pero no se liga orgánicamente a ninguno por la fijeza del parentesco, de la localidad o la profesión". Es, en cierto modo, un ser que, aunque percibible, es inasible, o mejor, incalificable dentro de unos parámetros dados, pues es "más que un tipo social que pudiera circunscribirse de una vez por todas (...) es una forma de socialidad misma como relación más allá del vagabundeo". ${ }^{8}$ Está ahí, pero de algún modo pertenece al afuera. Es su carácter ambiguo lo que le permite desplazarse con soltura por las distintas superficies de la ciudad; son el urbanita y la urbanita avezados en el arte de los tránsitos y las interacciones efímeras, que no pierden la coraza que los resguarda del tumulto y las miradas de los demás y que los mantiene en todo momento a una prudente distancia en la proximidad física que impone el hecho de compartir un espacio altamente denso. Así, el extranjero es el ciudadano por excelencia en una doble acepción: representa una experiencia

\footnotetext{
${ }^{6}$ La inatención de urbanidad "consiste en mostrarle al otro que se lo ha visto y que se está atento a su presencia (él mismo debe hacer lo propio) y, un instante más tarde, distraer la atención para hacerle comprender que no es objeto de una curiosidad o de una intención particular. Al hacer este gesto de cortesía visual, la mirada del primero puede cruzarse con la del otro, sin por ello autorizarse un 'reconocimiento'. Cuando el intercambio se desarrolla en la calle, entre dos transeúntes, la inatención de urbanidad toma a veces la siguiente forma: miramos al otro a dos metros aproximadamente; durante ese tiempo, se reparten por gestos los dos costados de la calle, luego se bajan los ojos en el momento en que el otro pasa, como si se tratara de un intercambio de semáforos. Éste es, probablemente, el menor de los rituales interpersonales, pero el que regula constantemente nuestros intercambios en sociedad". Goffman en Isaac Joseph, Erving Goffman y la microsociología, Gedisa, Barcelona, 1999, p. 77-78
}

${ }^{7}$ Georg Simmel, Sociología 2. Estudios sobre las formas de socialización, Revista de Occidente, Madrid, 1977, p. 716-717.

8 Ibidem, p. 717 


\section{perifèria}

Número 10, Junio 2009

\section{www.periferia.name}

compartida de esos trazos de vida urbana, pero también es una individualidad excepcional que acumula y particulariza esas experiencias urbanas. ${ }^{9}$

Es también el flâneur de Baudelaire que surge en el Paris decimonónico y que Benjamín recuperó para mostrar ese carácter ambiguo y perspicaz del paseante que se desplaza con liquidez por las calles de la ciudad; ${ }^{10}$ paseante que se convierte en voyeurista del espectáculo de la calle, observando su movimiento incesante y confundiéndose entre la multitud sin despertar sospechas, justamente porque conoce como nadie el arte de la representación y la máscara. ${ }^{11}$ Se mueve a través de calles, plazas, arcadas experimentando en cierta medida ese mundo de significados alegóricos de las grandes ciudades; sus políticas de paseo de algún modo instauran el nacimiento de una nueva subjetividad urbana. Este flâneur moderno sin embargo no encuentra las connotaciones del peripatético de Sócrates, pues no busca un público que escuche sus diálogos - de hecho no tiene nada que contar, se limita a mirar-, su lucha particular parece consistir en ser uno más dentro de la muchedumbre de la calle. Es, si se quiere, un paradigma de lo que pudiera ser ese derecho a la indiferencia, a que cualquier persona pueda trasegar por donde quiera sin que se le tenga en cuenta. Ambos, el extranjero y el flâneur, representan en definitiva una misma cosa: un tipo de actor social que se constituye en una forma de sociabilidad emblemática de la ciudad, la personificación de un modo de ser móvil, individual, cosmopolita, excéntrico, que navega dentro de relaciones contingentes, cambiantes, transitorias y frecuentes, dentro de espacios igualmente móviles y en constante transición.

\footnotetext{
9 Lorenza Mondada, Décrire la Ville. La construction des savoirs urbains dans l'interaction et dans le texte, Anthropos, París, 2000, p. 52.

10 Véanse Walter Benjamín, Historias y relatos, Muchnik Editores, Barcelona, 2000, y Graeme Guilloch, Myth and Metropolis (Walter Benjamín and the City), Polity Press, London, 1996

${ }^{11}$ La figura del flâneur aún continua siendo polémica y contradictoria, y plagada de un cierto carácter etnocéntrico y sexista en el sentido de que pareciera que esa figura inaugurada por Baudelaire, y luego retomada con tanta lucidez por Benjamín, presentara una experiencia urbana exclusivamente masculina, una encarnación de la mirada del varón sobre la ciudad. Pues en el siglo XIX la mujer no tenía la misma libertad de movimientos en los espacios públicos que los hombres y aún hoy, pese a la introducción definitiva de la mujer en la esfera laboral que la ha sacado de las paredes de la casa para adentrarse definitivamente en el reino público, sus tránsitos fluidos por cualquier espacio-tiempo de la ciudad constituyen, al menos en principio, una cuestión de fe. Así que la construcción de un abordaje de la ciudad desde una mirada femenina, la de la flâneuse, es un proceso que apenas comienza.
} 


\section{perifèria}

Número 10, Junio 2009

www.periferia. name

\section{La ciudad desde la filosofía}

Antes de proseguir con las implicaciones de la vida en la ciudad, parece al menos sugerente hacer una digresión en torno a la manera cómo está ha sido percibida por la filosofía sin otra pretensión mayor que no sea la de mostrar esas visiones generales en torno a la misma. De hecho, en pensadores como Rousseau o Nietzsche, por citar sólo dos ejemplos, se pueden encontrar algunas alusiones literales a la vida en la ciudad, si bien desde perspectivas distintas, pero que de alguna manera aportan algunas luces para entender lo que hoy se considera como vida urbana. En sus Carta a D'Alembert Rousseau hace una crítica a la vida metropolitana a través del rechazo al mundo de apariencias que se da en las grandes ciudades junto con la pérdida de los sentimientos morales. ${ }^{12}$ Por ello alaba la vida de los pueblos donde la gente se muestra tal como es, en una perfecta combinación con los sentimientos morales: lo uno refleja lo otro. Para entender esta posición del autor del Emilio es necesario tener en cuenta su percepción del declive de la cultura de los tiempos modernos, particularmente porque ésta ha sido presa del poder del dinero. El hombre ha perdido su estado natural y nunca puede recuperarlo. La única posibilidad para enriquecerlo consiste en un equilibrio entre el estado perdido de la naturaleza y el estado de la cultura por el otro. Tal estado de equilibrio no puede darse en los escenarios urbanos presos de la especulación económica y de la apariencia social. Solo puede ser vivido, mantenido y corporizado en un pueblo pequeño que tenga una constitución republicana y donde reine la transparencia en las relaciones sociales. Este tipo de consideración pudo tener cierta influencia en la forma como se desarrolló el urbanismo en épocas posteriores que de alguna manera se refleja en la preocupación por el tremendo crecimiento de la ciudad y por el rechazo a los daños ecológicos y las devastaciones que las ciudades industriales podrían llegar a causar. En ese sentido la Garden City de Howard está muy próxima a los planteamientos de Rousseau, lo mismo que la cité radiéuse de Le Corbusier. Otros, como Mumford, no rechazaban ninguna institución

\footnotetext{
12J ean-J acques Rousseau, Carta a D'Alembert, Tecnos, Madrid, 1994.
} 


\section{perifèria}

Número 10, Junio 2009

\section{www.periferia.name}

urbana, pero si propugnaban por poner límite al crecimiento desaforado de las ciudades pues a la larga éste significaría su declinación, su muerte. ${ }^{13}$

Nietzsche, mientras tanto, en su Así habló Zaratustra, de 1880, hace una crítica aguda a la metrópoli y al dinero que la corrompe. ${ }^{14} \mathrm{El}$ héroe nietzschiano circula por los alrededores de la gran ciudad evitando entrar en ella, quizá para no contaminarse con ese mundo abyecto aplastado por un signo económico que marca los cuerpos y las conciencias. “Oh, Zaratustra, aquí está la gran ciudad: aquí no tienes nada que buscar y todo que perder"15 advierte el necio a Zaratustra mientras le dice, "El dios de los ejércitos no es el dios de las barras de oro; el príncipe propone pero ¡el tendero dispone! (...) escupe a la ciudad de las almas aplastadas y de los pechos estrechos, de los ojos afilados, de los dedos viscosos (...) en donde todo lo podrido, desacreditado, lascivo, sombrío, superputrefacto, ulcerado, conjurado supura todo junto...". Y entonces Zaratustra contempla la ciudad y reflexiona: “iAy de esta gran ciudad! ¡Yo quisiera ver ya la columna de fuego que ha de consumirla!". ${ }^{16} \mathrm{Y}$ pasa de largo. El aire corrosivo lo envuelve todo; allí los placeres y los vicios tienen su casa, y eso significaría su destrucción por eso Nietzsche saca a su héroe de la ciudad y su cultura y lo envía a la montaña donde es posible vislumbrar ese superhombre, que es la negación de Dios. Con esto se da por descartado que la modernidad pueda encontrar su origen en el reino de la metrópolis y que allí pueda surgir el hombre que se trascienda así mismo. "Donde no se puede continuar amando se debe -ipasar de largo!".

Pero esas no son las únicas alusiones filosóficas a la vida urbana; de hecho en un interesante ensayo, Hainz Paetzold atiende a algunas de ellas -literales y metafóricas- que van de Descartes a Lefebvre, mostrando tres líneas generales a

\footnotetext{
${ }^{13}$ Sobre la tradición antiurbana que se desarrolla a lo largo del siglo XIX, véase Marshall Berman, Todo lo sólido se desvanece en el aire: la experiencia de la modernidad, Siglo XXI, Madrid, 1988.

${ }^{14}$ Friedrich Nietzsche, Así habló Zaratustra, Alianza Editorial, Madrid, 1998, p. 273

15 Ibidem, p. 275

16 Ibidem, p. 277
} 


\section{perifèria}

Número 10, Junio 2009

\section{www.periferia.name}

través de las cuales se conciben la ciudad y la vida urbana. ${ }^{17}$ Una línea a la que se podría denominar como de rechazo a la vida en la ciudad, en donde ésta es vista como un ser superficial y siempre bajo el influjo de la mentalidad intolerante de los comerciantes (allí estarían Nietzsche, Oswald Spengler y Martin Heidegger). ${ }^{18}$ Una segunda línea esbozada combina de un lado el rechazo a la gran ciudad y, del otro, una exaltación de la vida tranquila de los pueblos o ciudades pequeñas por considerar que sólo allí se puede encontrar un alto grado de transparencia en la vida social que no es posible hallar en las grandes metrópolis, línea comenzada por Rousseau y desarrollada de alguna u otra manera por Howard, Mumford y otros urbanistas contemporáneos que ven el "peligro" en que se convierte una ciudad que se sale de sus cauces. La tercera tendencia considera a la ciudad como un marco de posibilidades contradictorias, pues en el seno de una disposición plena a la utopía también puede viajar el gusano de la catástrofe. Dentro de esta tradición, la ciudad y los procesos de modernización tienen una doble faz, pues por un lado el abrupto e incontrolado proceso de urbanización produce graves consecuencias sociales y ambientales y un predominio de la ciudad sobre el campo, y, por el otro, la enorme cantidad de comodidades que se concentran dentro del espacio urbano sólo pueden ser apropiadas en su interior. Lo cual implica en principio una relación dialéctica entre ambos elementos en el seno de la vida urbana. A esta línea inaugurada de alguna manera por Marx y Engels y Weber muchas nuevas ideas han sido añadidas, desde las Simmel o Walter Benjamín, hasta H. Lefebvre, entre otros.

\section{Ciudad y vida urbana}

Los planteamientos anteriores sugieren de antemano la asunción de una noción de ciudad que supera aquella relacionada con la disposición espacial, es decir, como un mero lugar físico donde se asientan los distintos sistemas de poder y se encaminan más bien a considerarla como un modo de vida, esto es, como un espacio donde surgen y se desarrollan maneras vitales de características singulares. Y no podría

\footnotetext{
17 Heinz Paetzold, "The philosophical notion of city", (from the City Life), en The city cultures readers, Malcom Miles, Tim Hall and Lain Borden, (eds), Routledge, Londres, 2000.

18 Ibidem, p. 208.
} 


\section{perifèria}

Número 10, Junio 2009

\section{www.periferia.name}

ser de otra manera si se tienen en cuenta algunos rasgos fundamentales de las grandes metrópolis ligados a las nociones de dimensión, densidad y heterogeneidad, a partir de las cuales la ciudad sería una composición espacial definida por el asentamiento de un amplio conjunto de construcciones estables en la que reside una colonia humana conformada más bien por desconocidos entre sí. Ahora bien, desde la perspectiva de aquella primera ciencia social de la ciudad, ésta deja de ser un mero objeto y se convierte en una manera de vivir marcada por "la aglomeración, esto es, densidad de población, de objetos producidos y de símbolos", que "condiciona la interacción de los individuos y de los grupos que viven en ella...". ${ }^{19}$ Esta acepción señala un punto de inflexión en el estudio de la ciudad que se sale de los marcos de esa ecología espontánea tan importante para la Escuela de Chicago y se adentra en esas formas sociales urbanas registrables que se reproducen en un contexto diverso y heterogéneo y en las que cada cual vive indefectiblemente inmerso en un mundo de extraños plagado de relaciones nunca mejor dicho- sobre la marcha y por lo tanto superficiales.

Esa distinción entre ciudad y vida urbana sugerida implícitamente por Wirth, es formalizada por Henri Lefebvre, quien dilucida la primera como "una realidad presente, inmediata, dato práctico sensible, arquitectónico", y la segunda como "una realidad social compuesta por relaciones a concebir, a construir o reconstruir". En tal sentido la ciudad es un sitio y lo urbano "algo parecido a una ciudad efímera", pues es ante todo "una forma radical de espacio social, escenario y producto de lo colectivo haciéndose así mismo, un territorio desterritorializado en que no hay objetos sino relaciones diagramáticas entre objetos, bucles, nexos sometidos a un estado de excitación permanente". ${ }^{20}$ Estos planteamientos no entrañan una separación, confusión o reducción a la "inmediatez sensible" de las relaciones existentes entre ambas dimensiones, pues lo urbano, la vida urbana, no

\footnotetext{
19 Louis Wirth, "El urbanismo como forma de vida", en M. Fernández Martorell (ed.), Leer la ciudad, Barcelona, Icaria, 1988. Véase también Richard Sennet, Vida urbana e identidad personal, Península, Barcelona, 1975, pp. 95-104

${ }^{20}$ Manuel Delgado, "De la ciudad concebida la ciudad practicada", Archipiélago, 62 (septiembre 2004), pp. 7-13.
} 


\section{perifèria}

Número 10, Junio 2009

\section{www.periferia.name}

puede prescindir de una base práctico-sensible, de una morfología en la cual se origina y cobra sentido. Desde esa perspectiva, los elementos de la espacialidad urbana se pueden ver desde dos puntos significantes: por un lado las calles pueden ser percibidas como un lugar de encuentro, como un espectáculo diverso, en el cual se es actor y espectador al mismo tiempo, en una ejecución casi coreográfica (la calle es la ejecución de un ballet, dice Jane Jacobs ${ }^{21}$ ); pero, del otro lado, los espacios urbanos actuales, en cuanto formalizaciones arquitectónicas, son también colonizados por la economía del consumo y la ostentación de comodidades. Sea como fuere, la ciudad implica la síntesis y la multiplicación de lo divergente y lo dispar; pero la cosa más importante es la apropiación de todos sus productos y su uso. Como escribe Lefebvre: "El derecho a la ciudad (...) sólo puede formularse como derecho a la vida urbana, transformada, renovada. Poco importa que el tejido urbano encierre el campo y lo que subsiste de vida campesina, con tal que 'lo urbano', lugar de encuentro, prioridad del valor de uso, inscripción en el espacio de un tiempo promovido al rango de bien supremo entre los bienes, encuentre su base morfológica, su realización práctico-sensible". ${ }^{22}$

Para matizar lo dicho hasta aquí, está claro que la ciudad no se reduce a la vida urbana y viceversa, pues podría haber ciudades con características no urbanas (o pueblos grandes que sí las tengan), y elementos urbanos más allá de las ciudades. Ese "poco importa que lo urbano encierre el campo" de la cita anterior ya intenta problematizar una relación que no es estática, ni definitiva, sino que se va construyendo a partir de las prácticas y los usos, de un estar dentro de las urbes. No obstante, se puede decir que posiblemente algunas características de la ciudad incidan de manera importante en el surgimiento de lo urbano, tal como lo intuyó Louis Wirth, pero sin que esas sean determinantes o condición sine quanon para

\footnotetext{
21 Jacobs, Muerte y vida de las grandes ciudades, p. 17

${ }^{22}$ Henri Lefebvre, El derecho a la ciudad, Península, Barcelona, p, 138. Ese derecho a la ciudad se aleja por supuesto del urbanismo de Haussman y el funcionalismo de Le Corbusier, que excluyen a los menos privilegiados de los centros urbanos, así como de cualquier otro intento de domesticar el espacio urbano poniendo cortapisas a las apropiaciones no controladas de calles y demás lugares de encuentros y tránsitos. Jane Jacobs habla de esta “programación urbanística anti-ciudades que podía dar lugar a reales y verdaderas ciudadelas de iniquidad y perfidia", cuyo promotor fue Le Corbusier y su ciudad radiante. Muerte y vida de las grandes ciudades, p. 25
} 


\section{perifèria}

Número 10, Junio 2009

\section{www.periferia.name}

que éste se produzca. En ese sentido su importancia radica en que facilitan la irrupción de una forma social visible en ciertas partes de la ciudad, esto es, en los lugares públicos o semipúblicos, como calles, plazas, parques, bares, centros comerciales y en todos aquellos escenarios en que pueda observase lo que Jean Remy llamaba urbanización, "ese proceso consistente en integrar crecientemente la movilidad espacial en la vida cotidiana, hasta un punto en que ésta queda vertebrada por aquélla". ${ }^{23}$

En términos generales lo urbano es sólo una forma de vida más que se origina y se visibiliza preferentemente, pero no exclusivamente, en la metrópoli. La complejidad de ésta reside justo en que allí se establecen de manera permanente y rutinaria los tres reinos sociales de los que habla Lyn $\mathrm{H}$. Lofland: el reino privado, el comunitario y el público, cuyas fronteras se pueden percibir líquidas y difusas. ${ }^{24}$ El reino privado (the private realm) tiene que ver con los lazos que se establecen entre miembros de un grupo primario que pueden estar localizados dentro de la casa y las redes personales (el mundo de la casa y los amigos); el reino comunitario (the parochial realm) se caracteriza por el sentido de concordancia o pertenencia entre conocidos y vecinos que se involucran en redes interpersonales localizadas dentro de comunidades (el lugar de trabajo, asociaciones o las redes de conocidos); el reino público (the public realm), por su parte, es el mundo de extraños y de la calle, que sólo surge a partir de la invención de la ciudad. Éste únicamente puede darse en el espacio público cuyos perfiles configurantes lo hacen distinto de las otras esferas de la actividad social, de los otros territorios sociales, básicamente porque en él los individuos en copresencia tienden a ser personalmente desconocidos o sólo categorialmente conocidos los unos con los otros. Estos reinos, como territorios sociales, están localizados dentro del marco material de las ciudades pero no se definen por ese espacio físico, sino por las formas relacionales

\footnotetext{
${ }^{23}$ Jean Remy y Liliane Voyé, La ville : vers une nouvelle definition?, L'Harmattan, París, 1992, p. 14.

${ }^{24}$ Mediante la distinción de esos tres "reinos" (private realm, parochial realm, public realm) Lyn H. Lofland trasciende la dicotomía público/privado para explicar el fenómeno urbano y enunciar los diferentes tipos de vida que allí pueden darse. Véase su The Public Realm. Exploring the city's quintessential social territory. Aldine de Gruyter, Nueva York, 1998, pp. 10 -12
} 


\section{perifèria}

Número 10, Junio 2009

\section{www.periferia.name}

predominantes. De esa manera un reino privado existe cuando la forma relacional dominante que se encuentra en algún espacio físico es la intimidad; un reino comunitario, cuando la forma dominante de relación es comunal, y un reino público, cuando la forma dominante es entre extraños o conocidos categoriales. ${ }^{25}$ Así que, como se advirtió antes, la forma de relación que interesa en este esbozo teórico es justamente aquella que se manifiesta entre desconocidos o conocidos de vista cuyo espectro parece recorrer los espacios públicos y no otras enmarcadas dentro del vecindario, asociaciones, familias y otras corporaciones. Desde esa perspectiva, se apuesta por una mirada a las minucias cotidianas, detritus de una sociedad que parece des-bordarse a sí misma.

Aunque sería reduccionista decir que la ciudad como tal es sólo lo urbano, también está claro que sin esa agitación constante producida por los habitantes en sus formas de hacer, en los tránsitos y recorridos a través de los múltiples espacios, la ciudad, en su sentido pleno, no existiría. Pues, como se ha visto, ella no es sólo la forma ni las líneas que señalan su perfil (un objeto), sino la marejada de seres que la viven, la sueñan, la evocan, la re-memoran y la transitan, en un constante cruce de experiencias y sentidos. Allí la vida social hierve y se corporeiza en cientos de movimientos, prácticas y apropiaciones de su espacio público: la materia primigenia de lo urbano. Este espacio social es permanentemente construido a través de las vivencias y de las prácticas que son el reflejo de muchas realidades, inmersas en, retomando una expresión de Borges, un infinito juego de azares y que aluden a ciertas regularidades inestables esbozadas por Lefebvre en torno al espacio social: “Los grandes movimientos, los ritmos vastos, las grandes olas se interfieren, se chocan. Los pequeños movimientos se compenetran; cada lugar social no puede, por lo tanto, comprenderse sino a través de su doble determinación: empujado, arrastrado, a veces fracturado por los grandes movimientos -aquellos que producen

\footnotetext{
${ }^{25}$ I bidem pp. 12-15.
} 


\section{perifèria}

Número 10, Junio 2009

www.periferia. name

las interferencias-; pero al mismo tiempo atravesado, penetrado por los pequeños movimientos, los de las redes y los renglones". ${ }^{26}$

En resumen, la vida urbana, en el sentido que se ha venido exponiendo aquí, sólo se produce y visibiliza con todos sus matices en el espacio público de las grandes ciudades. Éste se convierte en el escenario no de una sociedad estructurada, hecha, sino en una superficie en que se desliza y actúa el "animal limitado de las ciudades", los hombres y mujeres de una "comunidad estructuralmente inconclusa" tal como lo advirtiera J oseph, es decir de una sociedad forjándose constantemente, de la cual sólo se perciben esas formas efímeras, fragmentarias que parecen estar en un constante hacer y deshacer y que son el reflejo de una realidad pixelada al infinito. ${ }^{27} \mathrm{Y}$ acerca de esas formas lábiles y esos personajes anónimos de la calle, cuerpos que se desplazan de manera concertada incluso en las ocasiones más polémicas, es que este desglose teórico cobra sentido.

\section{Lo urbano y el espacio público}

Como se ha venido diciendo, la ciudad es más que un territorio desproporcionado y conflictivo y puede ser pensada como un escenario de donde surge y en que se desarrolla preferentemente un tipo de vida singular marcada por la tendencia a la dislocación y la desafiliación, eso que hemos convenido en llamar lo urbano. No de otra forma se entiende la convivencia más o menos feliz -en términos de tránsitos y desplazamientos- de esa concentración de extraños que allí se manifiesta, una concentración cuya organización mínima sería imposible sin los requerimientos básicos que permiten la emisión y recepción de señales casi siempre fugaces, que deben decodificarse al instante; de ahí las estrategias, negociaciones, pactos surgidos de manera imprevista e imprevisible, pero en la mayoría de las veces a tono con la situación. Emergencias válidas para ordenar una textura urbana cuya esencia se condensa en un marco al que podemos acordar llamar espacio público.

\footnotetext{
${ }^{26}$ Henri Lefebvre, La production de l'espace, 2eme édition, Editions Antrhopos, París, 1981, p. 105

27 Isaac Joseph, Retomar la ciudad, el espacio público como lugar de la acción, Universidad Pontificia Bolivariana, Medellín, 1999, p. 3.
} 


\section{perifèria}

Número 10, Junio 2009

\section{www.periferia.name}

Así pues, el espacio público de las ciudades se constituye por antonomasia en el lugar de lo urbano como urdimbre de relaciones efímeras y superficiales entre desconocidos o conocidos "de vista", centro de prácticas y movimientos fragmentarios y difícilmente asibles, pero casi siempre visibles. Es principalmente en el centro de las ciudades -entendido no en un sentido meramente geográfico, sino como el lugar de la centralidad urbana, lugar en que, parafraseando a Virgina Wolf, "las cosas se juntan"- donde se produce esa concentración de extraños que comparten temporalmente un espacio, en que, a través de la gestión de la mirada y el lenguaje corporal, comunican sus intenciones prácticas inmediatas, intenciones que aluden en principio a las formas de tránsito, esto es, a los desplazamientos y a la ocupación espacial. Por tanto una calle se constituye en un escenario idóneo para toda clase de eventos, para interacciones efímeras y situaciones a veces insospechadas. Desde ese punto de vista el espacio público es ante todo un espacio social potencial, en el sentido de que se llena y cobra sentido en y por las prácticas y usos que allí se vertebran. Pero, ¿qué se entiende aquí por espacio público?

Dado que existen distintas definiciones de esa noción y de los términos que la componen, se hace precisa en este punto una toma de posición clara a la hora de establecer su significado aquí. El valor espacio se adopta asumiendo tanto su acepción kantiana, recogida por Simmel en tanto que "posibilidad de juntar", como la inspirada en Marx de Henri Lefebvre en tanto que producción, es decir como trabajo, labor de transformación por lo demás siempre inconclusa. El calificativo de público remite a lo que se somete al juicio y la contemplación de los demás, lo accesible a la mirada y a la opinión ajenas y tiene como antónimo lo privado, entendido como lo que se oculta, lo no mostrado, aquello que se sustrae a la consideración de los otros

Por espacio público se podría entender igualmente espacio de titularidad pública, noción que aquí se descarta. Espacio público es también uno de los conceptos que más se emplean en los discursos ideológicos hegemónicos y se refiere a lo que se imagina como escenario y concreción a la vez de aquellos principios de ciudadanía y civilidad en que en buena medida se basan, con voluntad legitimadora, ciertas 


\section{perifèria}

Número 10, Junio 2009

\section{www.periferia.name}

políticas de control y exclusión socio-espaciales. En un sentido parecido, el urbanismo se refiere a los espacios públicos como uno de los escenarios predilectos en los que ejecutar la voluntad de los planificadores por apaciguar o mantener a raya lo urbano, identificado con la tendencia de la vida urbana a la inorganicidad y al enmarañamiento. Esa visión, que comparten de manera articulada tanto las instituciones políticas como el diseño urbano a su servicio, interpreta el espacio público como ese ámbito arquitecturizado y transparente, naturalmente abierto y democrático, en que es posible la ciudadanía universal, que habla del derecho de acceso y por tanto del derecho de uso sin ningún tipo de restricción a quien se demuestre competente para ello. Las fuentes teóricas de esa concepción tienen que ver con la filosofía política y la teoría comunicativa, para las cuales se trata de un espacio de debates, de controversia y de revelaciones que evocan el dispositivo democrático por excelencia; ahí está la esfera de la publicidad, en el sentido que, inspirándose en el republicanismo kantiano, le dieran Hannah Arendt y Habermas en sendos textos ya clásicos, ${ }^{28}$ esfera regida, según Joseph, "por el placer sociable de hablar, de conversar libremente y sin esfuerzo, apelando en estos discursos voluntaristas regularmente a la virtud de la concertación". ${ }^{29}$

La noción de espacio público que aquí se asume, en cambio, deriva de unas ciencias sociales que conceden primacía a las formas de vivir y al análisis de los espacios intersticiales y los vínculos escasamente estructurados que en ellos tienen lugar. Tal construcción está ligada entonces a los movimientos de la calle, vista como espaciamiento, como espacio social regido por la distancia dentro de la copresencia, sin que ello niegue la predisposición a una solidaridad básica. ${ }^{30}$ Espacio público viene a ser así una manera de aludir a un campo ampliado de la calle como institución social y lugar para la acción, de tal forma que abarque otros marcos emparentados con ella, a la par que diferenciables, a la manera de las

\footnotetext{
${ }^{28}$ Hanna Arendt, La condición humana, Paidós, Barcelona, 1998; Jürgen Harbermas, L'espace public. Archéologie de la publicité comme dimension constitutive, Payot, París, 1978.

${ }^{29}$ Isaac Joseph, "Introduction“, I. Joseph (ed.), Prendre place. Espace public et culture dramatique, Colloque de Cerisy, Editions recherches, París, 1995, p. 11.

30 Ibidem, p, 12
} 


\section{perifèria}

Número 10, Junio 2009

\section{www.periferia.name}

plazas, los vestíbulos de las estaciones, los centros comerciales, los transportes colectivos y, por supuesto, los parques urbanos, todos ellos espacios dispuestos para el encuentro, socialmente autoorganizados a partir de rituales de exposición y evitamiento.

Esta forma de concebir el espacio público -cuya génesis es por lo demás inequívocamente moderna- ${ }^{31}$ podría comprenderse también a partir de la conjunción de dos nociones que lo involucran y a las que ya se ha aludido: el espacio como producción -o mejor como coproducción- social y lo público como lugar de las visibilidades, de las puestas en común, donde tiene lugar una forma de interacción basada en lo superficial -lo que flota en la superficie- y lo visible, ámbito en que los copresentes han de confiar en la apariencia de los demás y dejarse guiar por los indicios de que son vehículo. Ello implica que ese espacio no es una realización en sí mismo, sino que está constituido -o mejor, en constitución- por prácticas, por representaciones simbólicas y discursos. En otras palabras, que es resultado interminable de vivencias y utilizaciones concretas, pues, como dice Lefebvre, una existencia social que no produzca su propio espacio no es más que una abstracción que no puede superar la esfera de lo ideológico o de lo cultural. ${ }^{32}$ Ello sugiere además que el espacio público es un ámbito virtual, por cuanto se puede ordenar de distinta manera según los movimientos, recorridos, usos de quienes lo viven y experimentan cotidianamente. En ese sentido, no sólo actúa como un marco material -fuente y recurso a la vez- sino que comprende las relaciones que allí establecen los individuos como usuarios-productores a partir de sus prácticas espaciales específicas, pues...

\footnotetext{
${ }^{31}$ No voy a detenerme en esos orígenes de la noción de espacio público que aquí se maneja en la irrupción de la sociedad moderna, en oposición a la sociedad tradicional, en la línea del contraste canónico entre Gemeinschaft y Geselschaft propuesta por Tönnies o entre sociedad urbana y sociedad folk de Robert Redfield y la Escuela de Chicago. Se asume aquí el axioma según el cual tal génesis se enraíza en profundas transformaciones culturales que afectaron, a partir de la revolución calvinista y el nuevo paradigma cartesiano, a la división entre lo interior y lo exterior, entre el mundo y las nuevas ideas sobre la subjetividad y el sujeto. Nada nuevo al respecto luego que Richard Sennett nos proveyera de la crónica crítica de tal proceso, a cuyas conclusiones me atengo. Véase al respecto, entre otras obras suyas, el fundamental El declive del hombre público, Península, Barcelona, 1974.
}

32 Lefebvre, La production de l'espace, p.131 


\section{perifèria}

Número 10, Junio 2009

\section{www. periferia.name}

El espacio (social) no es una cosa entre las cosas, un producto cualquiera entre los productos, pues envuelve las cosas producidas, comprende sus relaciones en su coexistencia y su simultaneidad: orden (relativo) y\o desorden (relativo). Es el resultado de un conjunto de operaciones, y no puede reducirse a un mero objeto (...) Efecto de acciones pasadas, permite acciones, las sugiere o prohíbe. Entre estas acciones, unas se producen, otras se consumen, es decir son fruto de la producción. El espacio social implica múltiples conocimientos. ${ }^{33}$

Esas prácticas espaciales también subvierten con frecuencia el orden establecido por los planificadores de espacio. En ese sentido Certeau ofrece una explicación casi lírica de cómo los comportamientos en el espacio público de la ciudad no se atienen a las intenciones de sus diseñadores, no se someten a ellas. Las ideologías dominantes y las fuerzas de poder - la polis- pueden ser subvertidas efectivamente por miríadas de microprácticas, de actos intencionales o de lecturas paralelas que los individuos hacen en la vida cotidiana y que retan efectivamente los modos dominantes de interacción. El paseo por la ciudad ocupa una posición particular en esas prácticas a través de las cuales es posible desafiar el orden urbano establecido. Las prácticas del caminante se constituyen en el eje sobre el cual se crea y se re-produce el espacio y que también vienen a metaforizar la realidad dinámica, fluida y casi incognoscible de la ciudad.

Cuando se escapa a las totalizaciones imaginarias del ojo, hay una extrañeza de lo cotidiano que no sale a la superficie, o cuya superficialidad es solamente un límite adelantado, un borde que se corta sobre lo visible. (...) Estas prácticas del espacio remiten a una forma específica de operaciones (de 'maneras de hacer'), a 'otra espacialidad' (una experiencia 'antropológica', poética y mítica del espacio), y a una esfera de influencia opaca y ciega de la

\footnotetext{
33 Ibidem, pp. 88-89.
} 


\section{perifèria}

Número 10, Junio 2009

\section{www.periferia.name}

ciudad habitada. Una ciudad trashumante, o metafórica, se insinúa así en el texto vivo de la ciudad planificada y legible. ${ }^{34}$

Por otro lado, como lugar de visibilidades, el espacio se constituye en una clase de territorio social de publicidad y publicación inmediata y efímera. Se aparece ante los demás y éstos ante los otros, en acciones que muestran una labor práctica nunca acabada, es decir, en un continuo presente. En ese contexto se da una preeminencia de la vista sobre los otros sentidos, pues ésta no sólo es un instrumento para la acción sino que es la acción misma. A través de la mirada se percibe la "identidad social" del otro, quedan al descubierto sus intenciones inmediatas, sus trayectorias y en consonancia con eso se sabrá como actuar. ${ }^{35} \mathrm{De}$ ahí ese tipo de interacción que se da en los espacios públicos y que Goffman distinguió entre no focalizada y focalizada, formas de comunicación interpersonal que resultan de la simple copresencia y que se constituyen como tales aun si la reciprocidad de las personas se reduce a la mera observabilidad mutua (como ocurre entre dos transeúntes que se cruzan en una calle). ${ }^{36}$ En ese contexto, la cortesía visual de la inatención es una forma importante de la interacción no focalizada, una manera de mirar que consiste en atenuar la observación y que se constituye en la primera etapa del encuentro. ${ }^{37}$ Las interacciones focalizadas están ligadas al sentido del lugar e implican una manutención compartida de un mismo foco visual, en una disposición cara a cara, esto es, de una determinada proximidad física. ${ }^{38}$ En ambos casos es importante la gestión de los gestos y las miradas que son las que en últimas determinan también el tipo de interacción, de tal manera que el paso de una a la otra se manifiesta, entre otras cosas, por un cambio

\footnotetext{
34 Michel de Certeau, La invención de lo cotidiano, Universidad Iberoamericana, México, 1996, p. 105. Cursivas del autor.

${ }^{35}$ Esa identidad social está enfocada en el sentido que efectivamente le da Goffman, para referirse a las categorías sociales a las que puede pertenecer o ver que pertenece un individuo: grupo de edades, sexo, clase, etc. Goffman, Relaciones en público, Alianza, Madrid, 1979, p. 195

${ }^{36}$ J oseph, Erving Goffman y la microsociología, p, 74

37 Ibidem, p. 78.

38 Ibidem, p. 73.
} 


\section{perifèria}

Número 10, Junio 2009

\section{www.periferia.name}

observable en la orientación visual sostenida dentro de una situación de copresencia. Estas formas visibles de interacción en ambientes urbanos equivaldrían de alguna manera a la oposición mirada focalizada/mirada no focalizada. ${ }^{39}$ Dentro del primer caso, las orientaciones visuales manifiestan una modalidad de participación en la interacción, asumiendo funciones pragmáticas, y dentro del segundo caso, actualizan un régimen de reconocimiento fundado en la no participación y la distancia a través de la cual se organiza la presencia mutua en el extrañamiento. Aquí los actores no se ven comprometidos en interacciones puntuales, salvo en aquellas acciones recíprocas a las que de alguna manera "obliga" una situación concreta, como desplazarse por la calle o por los pasillos de una estación del metro, sin participar por ello en acciones conjuntas. Aquí se habla de una política de la inatención, que implica una forma de tener en cuenta al otro pues se necesita de su acompañamiento concertado no sólo para los tránsitos callejeros, sino para mantener en juego las competencias de los miembros del grupo social conformado efímeramente, eso a lo que se da en llamar "la gente".

\section{El espacio público como lugar de la re-presentación y las visibilidades}

Ese carácter sensible del espacio público está dotado de unas cualidades materiales que le convierten, como se dice arriba, en un escenario de y para la observación, esto es, para mirar y ser mirado, para la visibilidad mutua. Y no podría ser de otra manera, porque es a partir de esas visibilidades que se ordena la ocupación del espacio en una simultaneidad organizada de prácticas protagonizadas, casi siempre, por extraños mutuos. Y quizá esa misma característica ha dado lugar a que tome fuerza, por ejemplo, la metáfora teatral planteada por Goffman a lo largo de su obra para comprender lo que allí ocurre. El escenario de representaciones

\footnotetext{
39 Louis Quéré y Dietrich Brezger, retoman los términos unfocussed look y focussed look de Sudnow, para mostrar el paso de una interacción no focalizada a una focalizada en donde la orientación visual es determinante. Cuando se muda de una a la otra se abandona la inatención de urbanidad que preserva la distancia en la copresencia y se manifiesta una suerte de intercambio recíproco que implica que ambas partes se han dado cuenta de sus respectivas presencias. En ese momento la atención en los detalles es esencial para organizar el curso de la acción. Véase Louis Quéré y Dietrich Brezger, “L'Etrangeté mutuelle des passants. Le mode de coexistence du public urbain“, Les Annales de la Recherche Urbaine no. 57-58, 1992, pp.92-93
} 


\section{perifèria}

Número 10, Junio 2009

\section{www.periferia.name}

goffmaniano intenta describir el trabajo de configuración que libran los participantes de una situación cualquiera de la vida cotidiana utilizando el lenguaje y las metáforas del cuadro teatral. Ello permite mostrar, entre otras cosas, cómo en los umbrales de la vida urbana, tiene lugar un trabajo de encuadre y reparación que puede ser interpretado, por una parte, como un ritual destinado a arreglar ofensas reales o virtuales, de alguna manera ligadas a la vulnerabilidad de los territorios de cada persona, y de otra parte, dice J oseph, como un lenguaje corporal productor de señales efectivas que señalan el inicio de una interacción o simplemente para distribuir la atención dentro de un millón de relaciones densas y dispares. ${ }^{40}$ Desde esa perspectiva, el parque, una calle o una plaza operan como un proscenio, como un decorado en que los actores/transeúntes/usuarios parecen seguir los lineamientos de una trama general, cuyo fin último podría ser la coexistencia sin sobresaltos a partir de la mutua previsibilidad de las acciones y las iniciativas. En ese contexto se ponen en juego las habilidades no sólo de representación, cuyo peso, como en el teatro, recae principalmente en el manejo corporal, en la gestión de las emociones y las miradas, sino también en la capacidad de improvisación, de actuar de manera coherente sobre la marcha y salir indemne de cualquier barrera o interferencia que pueda presentarse durante su actuación. A través de esos mecanismos es posible dar "forma y estructura dramática a ciertos temas que, de otro modo, resultan intangibles. Mediante el vestido, la gesticulación y la postura corporal podemos representar una lista heterogénea de cosas inmateriales que sólo tienen en común el hecho de que son significantes en nuestra vida...". ${ }^{41}$

No muy lejos, Habermas retoma la por demás vieja metáfora teatral para plantear la acción dramática como una superficie donde "todo agente puede controlar el

\footnotetext{
40 Isaac Joseph, “L'univers des rencontres et la vulnérabilité des engagements“, en Les Cahiers de Philosophie, no. 17, 1993, p. 223

${ }^{41}$ Goffman, Los momentos y sus hombres, Paidós, Barcelona, 1991, p. 188-189. Dice Goffman más adelante que una "cuestión fundamental en todas las interacciones cara a cara es la relación entre los participantes, es decir, qué es lo que cada uno de ellos puede asumir efectivamente que el otro sabe. Esta relación es efectivamente independiente de su contexto, y se extiende más allá de cualquier situación social a todas las ocasiones en que dos individuos se encuentran", p. 194
} 


\section{perifèria}

Número 10, Junio 2009

\section{www.periferia.name}

acceso de los demás a la esfera de los propios sentimientos, pensamientos, actitudes, deseos, etc., a la que sólo él tiene un acceso privilegiado. En la acción dramatúrgica los implicados aprovechan esta circunstancia y gobiernan su interacción regulando el acceso a la propia subjetividad". ${ }^{42}$ En ese contexto, los individuos se autoescenifican puesto que éstos no hacen gala de un comportamiento expedito y espontáneo, sino más bien de uno aprendido justamente en esas circunstancias prácticas y que en últimas responde a una "estilización de la expresión de las propias vivencias con vistas a los espectadores". Es decir, los individuos no hacen más que "utilizar" esos elementos elaborados para presentarse así mismos lo más convincente posible pero resguardando siempre esa parte fundamental de su subjetividad. Este concepto hace referencia principalmente a los participantes en una interacción cara a cara en la que hay una alternación en los papeles: los unos y los otros se constituyen en actores y público a la vez. El propósito último de cualquier actor es, como se ha dicho, suscitar una determinada imagen en el espectador, determinadas impresiones que comuniquen algunos elementos de sí adecuados en orden a participar en esas circunstancias particulares de la acción. Habermas se aleja un poco de esos parámetros limitativos de la dramaturgia e insiste en una acción comunicativa, dentro de una interacción cara a cara de dos o más individuos, donde se conjugue tanto su capacidad de lenguaje como de acción. Dentro de ese nivel importa entonces el consenso, el ponerse de acuerdo para actuar dentro de situaciones susceptibles de ello. En ese sentido, como para el interaccionismo simbólico, ${ }^{43}$ la interpretación se convierte en el eje

\footnotetext{
42 Jürgen Habermas, Teoría de la acción comunicativa I. Racionalidad de la acción y racionalización social, Taurus, Madrid, 1998, p. 124 De los cuatro conceptos que Habermas dilucida dentro de la teoría sociológica el de la acción teleológica, el de la acción regulada por normas, el de la acción dramática y el de la acción comunicativa, interesan los dos últimos porque plantean el problema de la metáfora teatral planteada por Goffman, de la que critica su visón hasta cierto punto limitada, pues sólo serviría para describir la orientación fenomenológica de la acción, no para comprenderla dentro de unos parámetros más generales, principalmente dentro del punto de vista teórico.

43 Para el interaccionismo simbólico, un individuo social es "un organismo capaz de entablar una interacción social consigo mismo formulándose indicaciones y respondiendo a las mismas", en ese sentido no se limita a responder a una acción recíproca, sino que el individuo es ante todo un organismo que debe reaccionar ante lo que percibe y su comportamiento respecto a lo que percibe "no es una respuesta motivada por tal presencia, sino una acción que surge como resultado de la interpretación..." (Herbert Blumer, El interaccionismo simbólico. Perspectiva y metodología, Hora, Barcelona, 1981, p.11).
} 


\section{perifèria}

Número 10, Junio 2009

\section{www.periferia.name}

sobre el cual girarían esos acuerdos situacionales y el lenguaje en el mecanismo a través del cual se concretan esas prácticas comunicativas. ${ }^{44}$

Se podría decir entonces que el modelo dramatúrgico empieza a complicarse en el mismo instante en que se constata que la trasposición al plano del espacio público no es completa porque el espectáculo teatral implica una "convocatoria pública que no corresponde a las escenas de la vida cotidiana", pues "los momentos de ésta son muy pocas veces buenas maneras sostenidas por una perspectiva única o por la mirada colectiva y focalizada de un agrupamiento". ${ }^{45}$ Ello implica que esos encuentros entre extraños, al contrario que en el teatro, se producen en un marco participativo que tiene por principio la heterogeneidad, la separación de públicos y el pasaje de un rol a otro, es decir, que en la experiencia de los tránsitos e interacciones urbanos los actores y espectadores se intercambian los papeles, mutan permanentemente de lugar y establecen nuevas representaciones en donde la improvisación tiene un carácter fundamental. A pesar de ello, el uso de la aproximación escenográfica, si bien no explica la esencia de la vida social, si contribuye a su descripción y comprensión. Así que su utilización es pertinente en cuanto facilita las herramientas para un acercamiento a un espacio público real, es decir, como argumento metodológico válido para el que la observación se convierte en el elemento fundamental para la percepción de las escenas que conforman la vida cotidiana, allí donde el lazo social se hace visible en el momento mismo de anudarse. Sea como fuere, no cabe duda que la metáfora teatral es uno de los acercamientos más importantes para la descripción y análisis del espacio público como lugar sensible y como marco para la acción social.

\footnotetext{
${ }^{44}$ Habermas, op.cit., p. 124.

45 Joseph, Erving Goffman y la microsociología... p. 71. Joseph critica sobre todo la relación frente de escenario/bastidores en el espacio público a la manera como Goffman la plantea en la metáfora teatral, pues, en éste, al ser los actores completamente visibles, deben mantener ese manejo de las representaciones constantemente. En cierta medida se está desnudo ya que cualquier acto o comportamiento inapropiado podrían constituirse en motivo de discordia y/o malentendidos. Eso implica que no hay lugar a ningún tipo de relajamiento que involucre una laxitud u olvido de ese manejo de las impresiones entre dos o más individuos que interactúan, todo lo contrario a lo que ocurre en la trasescena del espectáculo teatral.
} 


\section{perifèria}

Número 10, Junio 2009

\section{www. periferia. name}

Hasta aquí un punto relevante: el espacio público está dotado de unas características sensibles que permiten compararlo con un espectáculo teatral, pues existen unos actores/espectadores, un decorado, unos roles, una trama general y por supuesto una legibilidad en sus enunciados, todo lo que lo convierte en un lugar de y para la comunicación, para una actividad social al tiempo elemental y compleja, en el transcurso de la cual se publicita, se negocia, se actúa y también, porqué no decirlo, se confronta. Dentro de esos lineamientos es imprescindible insistir en la noción de espacio público como lugar de y para la acción, porque viene a condensar gran parte de lo enunciado hasta aquí. En ese caso, el espacio público se concibe, al menos inicialmente, como espacio de derechos - derecho de acceso y circulación que denotan la libertad pública-, como paisaje sensible - posee una materialidad sonora y visual-, y como espacio de ceremonias cívicas o de urbanidad - principio de cooperación en la copresencia. En estas aproximaciones quedan claras varias cosas: el sentido de accesibilidad general a ese tipo de espacio, su consideración como marco material y de comunicación, todo dentro de la afirmación de que éste es, en efecto, "el primero de los bienes públicos, que se concibe como visibilidad mutua, espacio de encuentro o puesto a disposición de la intención de cada uno" y que confirma que "todo bien público es una coproducción". ${ }^{46}$ Espacio que es un todo a la vez: concepción y uso, contexto para las actividades y realización de esas actividades. Lo anterior implica que es un espacio de encuentros y multiplicidad de perspectivas en donde se concreta la elaboración de un sentido común o mejor de una elaboración conjunta de los copresentes en determinada situación, esto es, de un comportamiento altamente cooperativo todo lo cual no excluye, antes al contrario, la posibilidad de choque y conflicto. $\mathrm{Y}$ todo ello indica además que es un espacio del movimiento, de concentración, de la dispersión y del pasaje. Por tanto la noción de espacio público, en palabras de Joseph, "remite no solamente a una realidad porosa donde se traslapan varios sistemas de actividad; sino también a una realidad conceptualmente inestable: abstracta y concreta,

\footnotetext{
${ }^{46}$ Isaac Joseph, «L'espace public comme lieu de l'action», Les Annales de la Recherche Urbaine, no. 57-
} 58,1993, p. 211 


\section{perifèria}

Número 10, Junio 2009

www.periferia.name

simbólicamente central y culturalmente dispersa, localizada y desubicada, espacial y hablada, episódica o intermitente y organizada y estructural" ${ }^{47}$

\section{Bibliografía}

Arendt, H. (1998). La Condición humana. Barcelona: Paidós.

Baudelaire, Ch. (1995). El pintor de la vida moderna. Murcia: Colegio de Arquitectos y Aparejadores de Murcia.

Benjamín, W. (2000) Historias y relatos. Barcelona: Muchnik Editores.

Berman, M. (1988). Todo lo sólido se desvanece en el aire: la experiencia de la modernidad. Madrid: Siglo XXI.

Bettini, V. (1998). Elementos de ecología urbana. Madrid: Trotta.

Blumer, H. (1981). El interaccionismo simbólico. Perspectivas y metodología. Barcelona: Hora S.A., pp 11.

Burguess, E. (1974). El crecimiento de la ciudad: introducción a un proyecto de investigación. En G. A. Theodorson (ed), Estudios de ecología urbana, Tomo I. Barcelona: Labor.

De Certeau, M. (1996). La invención de lo cotidiano .Vol.1: Artes de Hacer. México: universidad Iberoamericana, pp.105.

Delgado, M. (2004). De la ciudad concebida la ciudad practicada. Archipiélago, no. 62.

Goffman, E. (1979). Relaciones en público. Madrid: Alianza, pp.195

Goffman, E. (1991). Los momentos y sus hombres. Barcelona: Paidós, pp. 188-189

Habermas, J. (1998). Teoría de la acción comunicativa I. Racionalidad de la acción y racionalización social. Madrid: Taurus, pp. 124.

Hannerz, U. (1993). Exploración de la Ciudad. México: Fondo de cultura económica

\footnotetext{
${ }^{47}$ J oseph, Retomar la ciudad, p. 15. Cursivas del autor.
} 


\section{perifèria}

Número 10, Junio 2009

www.periferia. name

Jacobs, J. (1973). Muerte y vida de las grandes ciudades. Barcelona: Península.

Joseph, I. (1999). Erving Goffman y la microsociología. Barcelona: Gedisa, 1999.

Joseph, I. (1993). L'espace public comme lieu de l'action. Les Annales de la recherche urbaine, no. 57-58, pp. 211.

Joseph, I. (1993). L'univers des rencontres et la vulnérabilité des engagements. Les Cahiers de Philosophie, no. 17, pp. 223.

Joseph, I. (1995). Reprendre la Rue. En Isaac J oseph (comp.) Prendre Place espace public et culture dramatique. Cerissy: Recherches/plan urbain.

J oseph, I. (1999). Retomar la ciudad. El espacio como lugar de la acción. Medellín: universidad Nacional de Colombia.

Lefebvre, H. (1981) La production de l'espace. París: Antrhopos.

Lefebvre, H. (1969). El derecho a la ciudad. Barcelona: Península.

Lofland, L. H. (1998). The Public Realm. Exploring the city's quintessential social territory. Nueva York: Aldine de Gruyter.

Mondada, L. (2000). Décrire la Ville. La construction des savoirs urbains dans l'interaction et dens le texte. París: Anthropos.

Nietzsche, F. (1998). Así habló Zaratustra. Madrid: Alianza.

Paetzold, H. (2000). The Philosophical notion of the city. En Malcom Miles, Tim May y Lain Borden (eds) The city cultures Reader. Londres: Routlege.

Park, R. E. (1974). Ecología urbana. En G. A. Theodorson, Estudios de ecología urbana, Tomo I. Barcelona: Labor.

Park, R. E. (1999). La ciudad y otros ensayos de ecología urbana. Barcelona: Ediciones del Serbal.

Park, R. E. (1984). The City: suggestions for the investigation of human behavior in the urban environment. En R.E. Park y E. W. Burgess, The city: suggestions for the investigation of human behavior in the urban environment. Chicago: The University of Chicago Press. 


\section{perifèria}

\section{Número 10, Junio 2009}

\section{www. periferia.name}

Quéré, L. y Brezger, D. (1992). L'Etrangeté mutuelle des passants. Le mode de coexistence du public urbain. Les Annales de la Recherche Urbaine no. 57-58, pp. 92-93.

Remy, J. y Voyé, L. (1976). La ciudad y la urbanización. Madrid: Instituto de Estudios de Administración Local.

Rousseau, J J . (1994). Carta a D’Alembert. Madrid: Tecnos.

Sennet, R. (1974). El declive del hombre público. Barcelona: Península.

Simmel, G. (1998). Las grandes urbes y la vida del espíritu. El individuo y la libertad. Barcelona: Península.

Simmel, G. (1977). Sociología. Estudios sobre las formas de socialización. Vol. 2. Madrid: Revista de occidente.

Tarde, G. (1986). La opinión y la multitud. Madrid: Taurus.

Tarde, G. (1961). Estudios sociológicos, Las leyes sociales de la sociología. Córdoba: Ediciones Alessandri.

Wirth, Louis. (1988). El urbanismo como forma de vida. En Fernández Martorell (ed.), Leer la ciudad. Barcelona: Icaria. 